\title{
Televisão e publicidade: ações convergentes
}

\author{
Maria Lília Dias de Castro ${ }^{1}$ \\ Universidade do Vale do Rio dos Sinos \\ mlilia@terra.com.br
}

\begin{abstract}
Resumo: Partindo de uma aproximação entre os universos da publicidade e da televisão, este trabalho busca inicialmente explorar apropriações e interfaces, para depois discutir e analisar um tipo de ação e / ou movimento em que praticamente esses fazeres se fundem, como é o caso do merchandising. Para tal, discute a noção de publicização como um movimento discursivo utilizado por essas mídias tanto para a difusão de informações e promoção de produtos, como pela propagação de ações de interesse público, passando pela divulgação de uma mesma emissora. No âmbito dessa comunicação a intenção é refletir sobre um tipo de discurso de publicização: aquele feito pela publicidade quando se propõe a invadir a programação para lançar seus produtos - o merchandising comercial - e sua relação com a telenovela.
\end{abstract}

Palavras-chave: Publicização; merchandising; posição narrativa; discurso; auto-referencialidade.

\begin{abstract}
Starting with the approach of two universes: the advertising and the television, this work initially explore appropriations and interfaces, after it argues and analyzes a type of action and/or movement where practically these activities are joined, that is the case of merchandising. For such, it argues the notion of to make public like a movement used by these medias as for the diffusion of information and promotion of products, like the propagation of action of public interest, as passing for itself spreading. In the scope of this communication the intention is to reflect on a type of to make public speech: that fact for the advertising when it is considered to invade the programming to launch its products - merchandising commercial - and its relation with the soap opera.
\end{abstract}

Key words: To make public; merchandising; narrative position; speech; reference of itself

\footnotetext{
${ }^{1}$ Professora do PPGCC da Universidade do Vale do Rio dos Sinos
} 
Resumen: Desde una proximidad entre los universos de la publicidad y de la televisión, este trabajo busca inicialmente investigar apropiaciones e interconexiones; tras debatir y analizar una acción y/o movimiento donde prácticamente esos hechos se unen: como exemplo el merchandising. Para ello, discute la noción de publicização como un movimiento discursivo utilizado por esos medios de comunicación, tanto para la difusión de informaciones y promoción de productos, como para la propagación de las acciones de interés público, hacia la divulgación de una emisora. En el ámbito de esa comunicación, la intención es pensar sobre un modelo de discurso de publicização: aquel hecho por la publicidad cuando se propone invadir la programación para lanzar sus productos - el merchandising comercial - y su relación con la telenovela.

Asociaciones: Publicização; merchandising; posición narrativa; discurso; autoreferencialidad.

Résumé: Partant d'un rapprochement entre les univers de la publicité et ceux de la télévision, ce travail cherche tout d'abord à exploiter des appropriations et des interfaces, pour discuter ensuite d'un type d'action et/ou mouvement sans en négliger une analyse approfondie car ce type d'action constitue un espace où ces faires se fondent : il s'agit du merchandising. Pour ce faire, on y discute de la notion de publicisation comme un mouvement discursif utilisé par ces médias aussi bien pour la diffusion d'informations et la promotion de produits que pour la propagation d'actions d'intérêrt public, touchant même la diffusion de la propre chaîne émettrice. Dans le cadre de cette communication, notre intention est de réfléchir à propos d'un type de discours de publicisation : celui pratiqué par la publicité quand celle-ci se propose d'envahir l'émission dans le but de lancer ses produits - le merchandising commercial - et son rapport avec le feuilleton télévisé.

Mots-clé: Publicisation; merchandising; position narrative; discours; auto-référentialité. 
O crescimento da televisão, nos últimos tempos, tem atraído, em especial, a atenção de pesquisadores, preocupados com a força de penetração dessa mídia e, naturalmente, com o poder que ela exerce junto ao público.

Em recente entrevista concedida ao programa Roda Viva (TVE, 11/04/05), o cineasta e jornalista Arnaldo Jabor afirmou que o melhor de seus filmes conseguiu, em termos de audiência, em torno de 4 ou 5 milhões de espectadores ao longo de dois anos. Em contraposição, as inserções que ele faz no Jornal Nacional atingem, de uma só vez, 50 milhões de espectadores. Segundo ele, essa diferença serve para mostrar a força inequívoca dessa mídia e a grande responsabilidade do crítico frente às posições que assume.

A reflexão em torno da televisão faz pensar em uma série de questões que cercam essa mídia: Quais as especificidades da mídia televisiva? Que lógicas sustentam sua produção? De que recursos se utiliza para divulgar seu fazer? Quais as características de seus diferentes discursos? Que efeitos ela espera do público? A partir dessas questões norteadoras, pensou-se em orientar a investigação na perspectiva de uma aproximação com o mundo da publicidade, tentando ver que tipo de relações esses dois "fazeres" têm em comum.

Pode parecer estranho aproximar esses universos, sobretudo quando se restringe à publicidade a ação de um anunciante no sentido de promover determinado produto, serviço ou marca com vistas à sua aceitação e ulterior aquisição por parte do público consumidor; enquanto, à televisão, se entende tanto o suporte de veiculação da publicidade, como a empresa que desenvolve uma ação de promoção junto ao público para conseguir adesão, traduzida em termos de audiência. Essa duplicidade de função assumida pela televisão torna ainda mais complexa sua condição, e mais difícil a aproximação.

Não obstante, sabe-se que a televisão, sobretudo a comercial, para ocupar espaço e consolidar força, criou vínculos com a publicidade não apenas pela necessidade de veicular, promover anunciantes que lhe assegurem 
sustentabilidade, como também pelo desejo de incorporar ao seu fazer o jeito glamoroso que sempre foi a marca obstinada da publicidade.

$\mathrm{Na}$ construção desta reflexão, buscou-se inicialmente propor uma aproximação entre as duas mídias, buscando explorar apropriações e interfaces, para depois, discutir e analisar um tipo de ação e / ou movimento em que praticamente esses fazeres se fundem, que é o caso do merchandising.

\section{Especificidades e convergências dos dois fazeres}

\section{a) publicidade}

Desde que a mídia televisão passou a desempenhar papel de destaque na sociedade, a publicidade firmou com ela parceria fundamental: de um lado, por tirar proveito da força de penetração da televisão para seus anunciantes; de outro, por garantir retorno financeiro significativo para qualquer emissora, traduzido em compra de espaços para anúncios comerciais.

A publicidade, tal como hoje é entendida, é uma forma de comunicação voltada para a divulgação positiva de produtos ou serviços com objetivo de despertar interesse de consumo. Com esse objetivo, funciona como uma espécie de ritual, em que dá a conhecer, a um público determinado, aspectos positivos e/ou vantagens de produto(s), serviço(s) ou marca(s), com vistas a obter a aceitação desse público. Essa produção normalmente se circunscreve a uma situação concreta, de envolvimento de sujeitos, a evidenciar o caráter dinâmico e interativo, como propunha Bakhtin. Por mais autoritário que seja o lugar do anunciante, por ser o autor do ritual, ele precisa lançar mão de movimentos que simulem uma outra relação, pelo menos de igualdade junto ao consumidor, para obter adesão e envolvimento.

Nessa condição, a publicidade se transforma em um verdadeiro jogo em que o anunciante tenta agir sobre o outro na tentativa de com-vencer. Por isso, a construção discursiva vai dar prioridade não ao quê mas ao como dizer, a ponto de o consumidor prestar atenção ao que está sendo mostrado. A busca 
desse como dizer pressupõe o uso de uma gama variada de recursos retóricos, e a conseqüente definição e adequação de estratégias a serem empregadas. Nesse embate, o consumidor sempre sabe qual seu papel, e decide se quer ou não participar do jogo que, nesse caso, se traduz em aceitação e/ou assentimento. Por isso é tão importante o papel do consumidor, pois é de sua ação que a publicidade passa a ter sentido: é ele quem vai comprovar a consistência da oferta, aceitando ou adquirindo o produto anunciado. Por mais envolvente e sedutora que seja a construção publicitária, na simulação de vantagens e benefícios, na projeção de um mundo de sonhos, no uso de testemunhos inconfundíveis, o verdadeiro resultado é a compra do produto.

Para conseguir essas projeções, a publicidade explora as linguagens verbal, visual, sonora, próprias da televisão, além de buscar, mais e mais, diversificação na sua maneira de dizer e/ou mostrar.

\section{b) televisão}

Atenta com a audiência que lhe dá sustentabilidade, a televisão, no cumprimento das funções de informar, educar e entreter, sempre se preocupou em ofertar produtos que sejam do agrado do público. Até porque, como empresa comercial, sua meta prioritária é a conquista do mercado, que se traduz em aumento de audiência e em atração de anunciante, acarretando a almejada posição de destaque frente ao concorrente e a conseqüente obtenção de lucro.

Não é sem fundamento dizer que qualquer inovação em televisão é acompanhada de estudos preliminares que assegurem minimamente a possibilidade de acerto da novidade para que, depois, ela se converta em garantia de lucro para a emissora. Nessa ótica, também a televisão tem como meta a construção de um discurso que mostre sua eficácia junto ao público e, indiretamente, dê uma idéia de sua posição no mercado. 
Para isso, na dupla função de veículo e de empresa, ela tem buscado desenvolver ações, explícitas e implícitas, e processos, diretos e indiretos, que possam de fato responder aos anseios do público e atrair sua atenção. Desde a construção da grade de programação, a escolha de um novo formato até a chamada de um programa, a televisão está buscando estratégias de ação que a aproximam daquelas usadas pela publicidade.

Guardadas as especificidades, é possível reconhecer um movimento crescente de proximidade entre esses fazeres. Aliás, é pontual e pertinente a afirmação de Delgado, com apoio de Mattelart, de que falar em

$$
\begin{aligned}
& \text { sociedad de la comunicación equivale casi a proclamar que la } \\
& \text { comunicación publicitária se está convertiendo en una técnica de } \\
& \text { gestión y organización de las relaciones entre los hombres } \\
& \text { (Delgado, 1997, p.203). }
\end{aligned}
$$

Isso equivale a dizer que a mídia, de modo geral, para efetivar o contato mais direto com o público, vem aprimorando a linguagem e refinando a ação intencionalmente manipuladora.

Tanto a televisão como a publicidade têm em comum o desejo de tornar público sua oferta (produto, marca ou serviço, para a publicidade; programação, para a televisão). Esse movimento amplo de divulgação que envolve tanto a compra de espaço por anunciantes externos como a divulgação de ações / programas feitos pela televisão atualiza o conceito de publicização. Mesmo não dicionarizado, o neologismo publicizar, e com ele publicização (termos hoje praticamente consagrados na área), tem, na sua constituição, a raiz comum public, à qual se agrega o sufixo izar, elemento lingüístico que exprime uma relação causal, factitiva, que resulta no entendimento de publicizar como a ação de tornar público algum fazer.

A publicização tem relação direta com movimentos de diferentes ordens - econômica, mercadológica, social, comercial -, utilizados por essas mídias tanto para difusão de informações e promoção de produtos, como para 
propagação de ações de interesse público e/ou caráter educativo, passando pela divulgação, inclusive, de uma mesma emissora.

De natureza bastante ampla, o discurso que manifesta a publicização ocupa diferentes espaços e pode constituir-se (1) de maneira autônoma, manifestado sob forma de anúncios de caráter publicitário, de inserções de patrocínio, de chamadas a outros programas, de exposição da logomarca, de ações relativas a campanhas sociais, etc.; (2) de forma difusa, inserido no interior dos produtos televisuais, caracterizando-se como uma outra voz que empresta valor distinto ao discurso proferido.

Nesse sentido, a publicização se desenha, de um lado, como um movimento preciso de divulgação / promoção; de outro, como um movimento discreto que vai envolvendo o público de maneira nem sempre declarada. A sutileza se traduz no jeito diferente, e mesmo impactante, de dizer e/ou de mostrar, capaz de cativar o público e de com ele estabelecer qualquer espécie de vínculo.

A reflexão em torno desse conceito, e as ações engendradas pela televisão e pela publicidade, é o foco de uma pesquisa maior que se propõe a explorar essa convergência. No âmbito desta comunicação, a intenção é refletir sobre um tipo de manifestação, aquele feito pela publicidade, quando se propõe a invadir a programação para lançar seus produtos: o merchandising comercial, e sua relação com a telenovela.

\section{Merchandising e posição na trama narrativa}

$\mathrm{Na}$ televisão, o merchandising funciona predominantemente como uma técnica promocional de divulgação de produtos, muitos dos quais já totalmente consagrados, para reforçar a imagem e consolidar a marca na mente do telespectador / consumidor.

Seu emprego na telenovela se prende a duas razões fundamentais: a influência que a telenovela exerce na vida das pessoas (dimensão emocional e 
social) e a comprovada eficiência de comercialização que ela reitera (dimensão econômica). Ele não só reflete sentimentos humanos, detonando um processo psíquico que atinge pessoas de diferentes classes sociais, através daquele universo de encanto proposto pela trama; como constitui um espaço de venda e de auxílio à venda, direta ou indireta, de tudo a ela relacionado. Com efeito, a telenovela é um espaço privilegiado de geração de novos estímulos e de consagração de conceitos, imagens e marcas, o que justifica a intensa associação da televisão com o meio publicitário que, hoje em dia, compromete mais 50\% do seu investimento nessa mídia.

O merchandising na novela mobiliza instâncias muito peculiares: de um lado, os anunciantes "compram” o espaço de acordo com o público que querem atingir, buscando sempre a maior audiência possível; de outro, a televisão tem assegurada a parceria no custeio da produção, viabilizando a própria realização telenovelística, além de permitir um valor adicional de salário a atores, autores ou diretores.

Essa forma de ação imprime um caráter híbrido à técnica: tanto significa como peça publicitária (embora não o seja), como adquire outro sentido quando inserido na narrativa da telenovela: ao ser abalizado pelo personagem ficcional, o produto/marca adquire outro valor. Por isso também o cuidado em utilizar atores que tenham mais afinidade com o público, uma vez que o tom que eles emprestam ao personagem da ficção reverte em credibilidade ao produto e, com certeza, garantia de sucesso.

Em se tratando dessa forma de merchandising, o desafio é investigar acerca da natureza e da posição que ele ocupa na trama.

Pontualmente o merchandising consiste na explicitação de um produto (marca ou serviço), seja pela referência explícita do personagem, seja pela sua posição estratégica no cenário, com vistas a influenciar o público e tentar transformá-lo em consumidor. Sua função é o efeito multiplicador. Para alargar o poder de ação do produto mostrado e / ou da idéia anunciada, ele 
visa à captação do telespectador, justamente no instante em que este está descontraído, desatento e, em conseqüência, mais receptivo. A ação é sutil, mas incisiva.

A intenção é claramente transformar esse produto / idéia em objeto de desejo, para que o telespectador se transforme em consumidor no seu cotidiano real. Isso porque qualquer vantagem ou benefício, trazido ao personagem no plano da ficção, deve ser capaz de reverter em conforto para o próprio telespectador.

Dessa forma, no nível da linguagem, o merchandising deixa bem claro seu jogo de planos: é o discurso de promoção sobreposto ao discurso de entretenimento (aparece dentro da cena da telenovela), que adquire, pela inserção na cena e/ou pela participação do personagem, uma terceira dimensão de sentido. Esse entendimento de um discurso dentro de outro assinala o caráter nitidamente dialógico da manifestação e o estatuto semiótico de gerador de sentidos.

Naturalmente o merchandising não é inocente, pois também rende benefícios a todos os que com ele se envolvem. Segundo Silvio de Abreu (em entrevista a Edgard de Amorim),

\section{todo mundo lucra com o merchandising que é feito com o consentimento do autor que recebe para escrevê-lo, com o consentimento do artista que recebe por aquela fala e com o consentimento do diretor que dirige a cena (Amorim, on-line).}

A escolha dos produtos que poderão entrar numa novela decorre de resposta a consultas, feitas diretamente pelo cliente ou pela agência de publicidade, ou de levantamento de oportunidades, que surgem a partir da sinopse de uma telenovela, antes mesmo de começar a gravação. No caso específico da Globo, existe um departamento de merchandising que, depois de contatos preliminares, procura o autor e diz qual anunciante quer aparecer na novela dele. Aceitos pelo autor, os produtos passam a ser inseridos na narrativa de acordo com as possibilidades da trama. É preciso sutileza na 
inserção de um produto, respeitando as condições de adequação (idéia certa, hora certa, ocasião certa) para assegurar a captura do telespectador. Caso contrário, uma referência forçada pode gerar o efeito oposto: desconforto e, até, rejeição.

Isso remete a uma outra questão relevante relacionada à posição do merchandising na trama: ele é simplesmente uma inserção de superfície ou tem a intenção de agir mais significativamente dentro da trama? Em outras palavras, é um fenômeno meramente discursivo ou um movimento de base que interfere no encadeamento dos fatos?

Quando a proposição tem relação com a constituição da trama, o merchandising parece interferir no encadeamento dos fatos. Nesse caso, ele está relacionado ao princípio organizador da narrativa e, nessa medida, depois de examinados os temas e detalhadas as situações que poderiam suscitar questões pertinentes e adequadas para a trama, influencia toda a produção discursiva.

O entendimento dessa espécie de merchandising é firmar um pacto com o telespectador, que é o chamado contrato de leitura. O importante na noção de contrato é a possibilidade comunicativa, o acordo, que ele firma, facultando a projeção de um enunciador e a proposta de um lugar para o destinatário. “ $O$ conceito de contrato de leitura implica que o discurso de um suporte ... seja um espaço imaginário onde percursos múltiplos são propostos”. ..., o que equivale a dizer que

o "discurso é um espaço habitado, cheio de atores, de cenários e de objetos, e ler 'é movimentar' esse universo, aceitando ou rejeitando, indo de preferência para a direita ou a esquerda, investindo maior ou menor esforço, escutando com um ouvido ou com dois" (Verón, 2004, p.236).

Pensar o merchandising nessa perspectiva é situá-lo em um outro patamar, capaz de sobredeterminar as condições do discurso a ser produzido na trama. 
Em síntese, a natureza dialógica e semiótica, responsável pela geração de sentidos, associada ao nível de reverberação que o merchandising traz à trama, confere complexidade e densidade a esse tipo de manifestação, e é nessa perspectiva que se vai examiná-lo.

\section{Análise na telenovela selecionada}

Senhora do destino foi, antes da atual América, a telenovela veiculada pela Rede Globo no horário nobre das oito da noite. Foi sobre esse pano de fundo que, como em todas as novelas, as tramas paralelas se desenvolveram: a família rica, com hábitos refinados e alguns preconceitos em relação aos menos favorecidos; o núcleo da família do bicheiro, responsável pela escola de samba; o núcleo que reproduziu os fatos da história brasileira de 1968: ditadura militar, repressão política, prisões e personagens ligados ao jornal Diário de Notícias que foi fechado pelo regime (primeira parte da trama).

O estudo do merchandising, dentro da novela, centrou-se nos últimos meses de veiculação, dezembro de 2004 até 12 de março de 2005 (capítulo final). De 29 de dezembro a 12 de fevereiro, foram gravadas semanas intercaladas e, depois dessa data, semanas seguidas. No total foram sete semanas de exame dos recursos publicitários inseridos na própria trama. A escolha pelo período final da novela tem íntima relação com o aumento da audiência e da maior procura por parte dos anunciantes. O início da gravação, junto às comemorações de final de ano, possibilitaria não apenas o favorecimento dos anúncios como a aproximação efetiva entre realidade e ficção.

O merchandising feito na novela girou, predominantemente, em torno de Maria do Carmo (Suzana Vieira), não apenas proprietária da loja de material de construção no subúrbio carioca, Vila de São Miguel, como uma personagem considerada exemplar para os padrões brasileiros. Foi uma personagem de bom coração, mãe exemplar e obstinada (jamais desistiu de encontrar a filha 
seqüestrada), além de ser mulher que soube lutar muito e conseguir sucesso na vida. O merchandising superou a marca das cem ações das antecessoras Celebridades e Mulheres Apaixonadas. Merece destaque a referência feita pela Revista Pro News ao anunciante Votorantim:

pela primeira vez na história da telenovela brasileira e do setor de material de construção, uma empresa desenvolve ação de marketing de cimentos voltada especificamente ao público final através de programa de grande impacto (Gomes, on-line).

A forma mais constante é a menção no texto que consiste na referência a determinado produto feita por algum personagem da novela, tentando fazer com que a fala seja o mais natural possível. Nessa menção, incluem-se as referências rápidas ao produto, e as ações mais incisivas, quando o personagem não apenas refere como tenta explicar a outro as vantagens do material.

No período estudado, e por explorar a protagonista Maria do Carmo, as maiores ocorrências foram na loja de materiais de construção, com os produtos:

- Votorantim (cimento e argamassa): o pedreiro na loja diz que aprendeu a "fazer misturas que não têm como dar errado, tipo água limpa, cimento certo..." (e mais outra inserção);

- Lukscolor (tintas): a vendedora da loja diz que "com essa tinta aí, não se precisa de outra", ao que Maria do Carmo reforça: "Lá isso é verdade, meninas. É meu nome que está em jogo. Por isso que eu faço questão de vender essa tinta aqui na loja, recomendar para minhas amigas e usar lá em casa" (e mais quatro inserções);

- Deca (materiais sanitários): um arquiteto, em visita à loja, fala de qualidade e diz que "a moda agora é transformar os banheiros em verdadeiros mini 'spas'” (e mais quatro inserções). 
Também houve referência a outros produtos:

- Caldo de picanha Maggi: quando a neta de Maria o Carmo, na cozinha, diz que "não conhecia este caldo";

- Vinho Malbec: quando o maitre e filho de Maria do Carmo, Viriato, pergunta se Moura "colocou o Malbec que chegou ontem na sugestão da carta de vinhos";

- Hidratante Natura: quando Gisela passa o produto no corpo e diz que "esse hidratante é tão cheiroso que dá vontade de usar como perfume" (e mais duas inserções);

- Filme "Xuxa e o tesouro da cidade perdida": quando Mikel diz que Hellen "era apaixonada pela Xuxa" e pergunta se ela sabia que estava passando um filme da atriz;

- Hotel Copacabana Palace: quando Laura diz a Guilhermina que "é fantástico vir tomar um chá na pérgula do Copa" (e mais duas inserções);

Outra forma é o destaque à marca em que, sem inserção direta na fala, os personagens usam o produto e / ou serviço, deixando bem claro ao telespectador a marca utilizada. É uma espécie de realce à marca de forma indireta. As referências desse tipo foram:

- Itaú Bankline: Maria Eduarda pede, por telefone, dinheiro emprestado à mãe, Gisela. Ambas estão em frente a seus laptops e utilizam a página do Itaú Bankline: Gisela diz que já deu "o primeiro clique" e, após alguns segundos, afirma já ter transferido o dinheiro para a filha e que "acabou este problema".

- Posto Ale: Edgard abastece o carro, e conversa com o frentista do posto, aparecendo nitidamente a marca quando ele chega e quando sai. 
Próximo a este último, está o estímulo visual que consiste na inserção do produto dentro do cenário, configurando toda a ambientação. Na telenovela, o exemplo mais característico é dado pela distribuidora mineira Ale Combustíveis, que chegou a construir um posto de gasolina cenográfico no Projac como parte do cenário, com a intenção não apenas de expor a marca ao público, como de associar o posto de gasolina a um lugar que está em processo de emancipação política. O posto de gasolina pretende ser o reflexo do progresso de Vila de São Miguel. Quando aparece sua logomarca, é sempre como pano de fundo de uma situação de diálogo qualquer: ou os personagens estão abastecendo, ou o carro estraga próximo daquele posto, mostrando esse anunciante em destaque.

Ainda dentro dessa categoria, aparecem as seguintes situações:

- Votorantin: Leandro e Giovanni conversam em frente à loja, e alguns homens descarregam sacos de cimento Votorantin;

- Portobello: Crescilda e Plínio conversam, tendo ao fundo produtos Portobello, duas vezes diretamente focalizados;

- Lukscolor: a marca é realçada ao fundo de duas cenas que se desenvolvem no cenário com pintura verde (mesmo tom das latas e com a logomarca do anunciante);

- Portobello, Lukscolor, Tigre, Sanix, Silent, Lumiex e Deca: adesivos colocados na parede da loja, funcionando como pano de fundo para os personagens envolvidos com a loja de materiais (nove inserções).

Uma peculiaridade no merchandising da novela foi a publicação do livro Cozinha de D. Clementina, com receitas da personagem de mesmo nome, em parceria com a Maggi (da Nestlé). O livro, confeccionado pela Editora Globo, teve sessão de autógrafos na telenovela, com o envolvimento de vários atores que a ela compareceram. Ao mesmo tempo, teve lançamento real em livrarias, no mês de dezembro, fundindo a realidade com a ficção da telinha. 
O caso mais pontual de merchandising é aquele que parece interferir na estrutura da novela. A protagonista Maria do Carmo, ou Senhora do Destino, representa aquele conjunto de valores - honestidade, coragem, espírito de luta - que todas as pessoas almejam. Segundo o autor Aguinaldo Silva, "uma pesquisa concluiu que a personagem representava, melhor que qualquer outra nos últimos tempos, o que o marketing considera o brasileiro exemplar”. Por isso, ela constituiu o fio condutor, a pauta marcante do vínculo com o telespectador.

A conjunção com os valores por ela representados, tão amplamente retomados ao longo da narrativa, foi reforçada na escolha da personagem para o enredo da escola de samba, também denominado Senhora do Destino. Todas as ações envolvendo a decisão e a definição daquele tema, a elaboração do samba enredo, os ensaios preparatórios e o culminante desfile na avenida real assinalaram o caráter auto-referencial da construção. É a novela que faz referência constante à própria novela.

A auto-referencialidade está nitidamente marcada em várias ocasiões:

- A escolha da personagem Maria do Carmo, Senhora do Destino, como protagonista da novela e tema da escola de samba (alusões diretas à trajetória da personagem quando ainda retirante em Belém de São Francisco, com os filhos menores: as dificuldades vividas e as vitórias obtidas);

- A criação do samba-enredo e o reforço aos valores (força, coragem, determinação) representados pela personagem (foi elaborado na trama e, depois, cantado nos ensaios, na transição de algumas cenas e no desfile final); 
A Senhora do Destino é força, é fé / É valente, é dona desse chão / Retirante do sertão, é alma, é coração / Com seus filhos, fugindo da fome e da dor / Em busca de sonhos de amor / Maria do Carmo chegou / Em meio à revolução / O povo lutando seguindo a canção

E a luta continua / Dia e noite, noite e dia / Quem podia imaginar o destino da Maria / (repete) Uma história, um caso de amor / O jornalista / O tempo passou, sem aviso chegou / O sambista Lá na Vila São Miguel / Que a vida recomeçou / Tratando sua gente com afeto e calor / No trabalho mostra seu valor

Alô, alô, Baixada / Diz o ditado, quem espera sempre alcança / Quem é bom já nasce feito / Nunca perde a esperança / (repete)

- As menções explícitas ao título do enredo (seis vezes) e o chamamento através do bordão: Olha a Senhora do Destino aí, gente!, repetido inúmeras vezes pelos organizadores da escola, refletindo a forma típica de invocação de uma escola de samba;

- A faixa com o nome Senhora do Destino, na quadra dos ensaios da escola e o néon frontal, com o mesmo nome, no primeiro carro alegórico do desfile (seis inserções).

Esse movimento recursivo configura uma forma peculiar de merchandising: trata-se da referência ao enredo da escola que remete também à própria novela, à personagem, e, sobretudo, aos valores que ela representa. Mais que tudo, trata-se de consolidar o produto televisivo na mente dos telespectadores, fazendo convergir um discurso de múltiplas vozes, fortemente auto-referencial. E essa convergência de valores, personagem, título, tema, samba-enredo confere um efeito de circularidade, retroalimentando o próprio produto.

O resultado é, com certeza, um tipo de proposta que interfere na narrativa, e acarreta uma multiplicidade de vozes e de efeitos de sentido.

\section{Conclusão}

A análise do merchandising comercial em Senhora do Destino possibilitou o reconhecimento desse discurso como uma estrutura dialógica 
que opera com várias vozes: é a voz promocional associada à voz ficcional, à qual se agrega o testemunho do personagem, conferindo um terceiro sentido capaz de garantir a credibilidade da oferta para o telespectador.

Quanto à forma de repercussão que traz à trama, o merchandising pode gerar duas possibilidades. Predominantemente situa-se no nível do discurso com a finalidade de apreender o telespectador para levá-lo ao consumo. Nessa condição ele não provoca grandes alterações na trama, limitando-se a pequenas inserções de fala, coladas à conduta dos personagens, ou a mostrar o produto no cenário, em ações localizadas. Essa possibilidade é confirmada no depoimento do diretor Gilberto Braga (durante o seminário sobre televisão realizado em Paris em março de 2005): quando há proposição de inserção, disse ele, normalmente os anunciantes já trazem o texto que desejam ver mencionado pelo personagem. Em decorrência, o diretor que aceita o merchandising incorpora aquela proposta e a insere na fala do personagem solicitado. Essas inserções ocorrem na superfície da trama, sob forma de menção na fala dos personagens, de colocação estratégica no cenário, ou, ainda, de detalhamento do personagem que explicita essas vantagens.

A análise permitiu o reconhecimento de uma outra forma de inserção: aquela que interfere nos rumos da história. É o caso explícito da conjunção entre personagem / título / tema de escola / samba-enredo que foram ações criadas para reforçar a personagem que, em verdadeiro processo circular, alimentava a novela e, mais que tudo, garantia o sucesso e a audiência da emissora, razão final de todo o investimento feito.

Em síntese, verdadeira regra do sistema capitalista, o merchandising é uma formulação explícita e velada de estímulo ao consumo, inserida no interior da telenovela. Sem vender nenhum produto, ele constitui um dos recursos mais eficazes de publicidade nas novelas nacionais. É uma técnica híbrida de promoção: oferta um produto e, ao mesmo tempo, esse produto adquire outro sentido no momento em que é abalizado por algum personagem 
da trama. Estrategicamente o merchandising opera na tensão fantasia e realidade, pois entra no jogo da ficção proposta e, a partir daí, busca transformar o público em consumidor real, efetivo; prazer e direcionamento, porque aproveita o momento de descontração do telespectador para impor-lhe produtos de consumo; obscuridade e clareza, pois usa, na trama, recursos explícitos de divulgação ao lado de movimentos velados; simplicidade e malícia, porque se propõe, de forma aparentemente ingênua, a fazer insinuações sobre produtos / serviços, com a nítida intenção de gerar mudanças nos hábitos do consumidor. Todos esses artifícios funcionam decisivamente na luta pela audiência, que é a condição básica para atrair anunciantes os quais, ao mesmo tempo, realimentam a emissora para investimento em novas atrações, além de auxiliar na manutenção do padrão de qualidade das novelas, tendo em vista o custo altíssimo de produção.

\section{Referências:}

ALMEIDA, H.B. Na TV: pressupostos de gênero, classe e raça que estruturam a programação. I simpósio internacional: o desafio da diferença, Salvador, UFBA, abr./2000, Grupo de trabalho 4, Disponível em: http://www.desafio.ufba.br/gt4-008.html Acesso em jan./2005.

AMORIM, Edgard Ribeiro de. O fascínio de Sílvio de Abreu. Revista d'art, São Paulo. Disponível em: http://sampa3.prodam.sp.gov.br/ccsp/linha/dart/revista2 Acesso em jan./2005.

BAKHTIN, M. Marxismo e filosofia da linguagem. São Paulo: Hucitec, 1981.

DUARTE, E. Sobre autoconvocação: metadiscurso, auto-reflexividade, autopromoção. In: . Televisão: ensaios metodológicos. Porto Alegre: Sulina, 2004. p.89-105.

ECO, U. Tevê: a transparência perdida. In: Viagem na irrealidade cotidiana. Rio de Janeiro: Nova Fronteira, 1984. p.182-204. 
FLOCH, J.M. Sémiotique, marketing et communication. 4.ed. Paris: PUF, 2003.

GOMES, I. Votorantim cimentos aposta em merchandising global. Pro News. Revista de Comunicação e Marketing. Disponível em: http://www.revistapronews.com.br/edicoes/6o/ mo3.html Acesso em jan./2005.

JOST, F. Seis lições sobre televisão. Porto Alegre: Sulina, 2004.

KOTLER, P. Administração e marketing. São Paulo: Atlas, 1974.

LIPOVETSKY, G. O império do efêmero. São Paulo: Companhia das Letras, 1989.

LUHMANN, N. La realidad de los medios de masas. México: Universidad Iberoamericana, Anthropos Editorial, 2000.

SCHIAVO, M. Merchandising social: uma estratégia de sócio-educação para grandes audiências. Rio de Janeiro: Universidade Gama Filho, 1995. Tese de livre-docência.

TRINDADE, E. Merchandising em telenovela: a estrutura de um discurso para o consumo. Portal de Relações Públicas e Transmarketintg, s/l, ago./2004. Disponível em: http://www.portalrp.com.br/bibliotecavirtual/publicidadeepropaganda/oo8o.htm. Acesso em jan./2005.

VERÓN, E. Fragmentos de um tecido. São Leopoldo: Unisinos, 2004. 